\title{
ON CHAOS IN BIBLIOMETRIC TERMINOLOGY
}

\author{
V.S. LAZAREV \\ Research Institute of Hematology and Blood Transfusion, 160 Dolginovsky Tract, Minsk 223059 (Belarus)
}

(Received June 23, 1995)

\begin{abstract}
On behalf of a case study of articles on bibliometric selection and ranking the variance in terminology of the properties of journals is shown: the same properties are called in various manners, while one and the same terms have different meanings. Similar inconsistencies are found in the terms denoting readers' activities which are studied in bibliometrics for the assessment of the use of periodicals. The author concludes that there are actually only two properties of periodicals that are quantitatively assessed, viz. "productivity" and "value". Their definitions are suggested for terminology standardization of general properties of journals and of readers' activities.
\end{abstract}

The problem of terminology standardization is of vital importance when we are to understand ourselves and to be understood by researchers and science policy makers with whom we communicate. My case study paper is devoted, first, to terminological chaos in the denomination of the specific properties of scientific journals as reflected by bibliometric assessment of their ability to correspond to the professional information needs of specialists in a concrete scientific discipline. Second, the paper points to the absence of a generalized term for the activities of the readers of scientific periodicals, which, in bibliometric studies, reflect the mentioned ability of periodicals.

Terminological chaos seems to be caused by carelessness about the nature of the specific properties under study which are quantitatively assessed in the process of selecting and ranking the periodicals: some authors seem not to be aware that a method used in a study reflects a certain concrete property of a periodical which is more specific than a general ability to correspond to the professional information needs of the specialists; others may think that such properties are somewhat conditional, derived from a method of bibliometric evaluation, and hardly existing by themselves as a piece of objective reality.

To give an example, here is a list of designations of properties used in papers published from 1978 to 1986: "productivity" (with four different meanings), 
"profitability", "significance" (2 meanings), "information significance", "scientific significance", "importance", "descriptiveness" (4 meanings), "quality", "utility", "worth", "value", "information value" ( 2 meanings), "readability", "information potential" etc. Let us begin with the initial meaning of the term "productivity":

Bradford wrote: "... the law of distribution of papers on a given subject in scientific periodicals may ... be stated: if scientific journals are arranged in order of decreasing productivity* of articles on a given subject, they may be divided into a nucleus of periodicals more particularly devoted to the subject and several groups or zones containing the same number of articles as the nucleus etc."1 ${ }^{1}$ Of course, this is not really a definition, but it is the most obvious prerequisite for it.

A more explicit definition of the term "productivity" used in information science can be relevant for our discussion: "Periodical publications productivity is a relative characteristics of a periodical, determined by the number of articles published in this periodical that relate to a given (selected) theme or a branch of knowledge". ${ }^{2}$ Since all the methods relevant for the quantitative assessment of the productivity are based on the count of publications, it is but natural to agree that 'productivity is the property of scientific periodicals to contain the articles relevant to a concrete subject, characterized by the quantity of such articles'. And it is reasonable to standardize this definition to prevent the possible further arbitrary use of the term. It is also important to note that the defined property is not artificial, not derived from a method, but exists by itself as an objective reality.

The case of "productivity" is simple since this property can be directly measured by the number of relevant articles de visu, and when we proceed to a count of abstracts and bibliographic descriptions in secondary information sources the intermedium is both obvious and minor. On the other hand, substances as "significance", "quality", "value" etc. can only be indirectly assessed by the measurement of certain indicators of an intermedium which may denote them.

Since they are not directly measured but reflected through the magnitudes of the results of the use of bibliometric methods in a probabilistic (stochastic) manner, ${ }^{3}$ while the methods themselves are cognized much better than the properties that they reflect (as operating with directly observed indicators), the cognition of such properties may be more sufficient if we start with the cognition of the methods. The oldest group of methods of bibliometric assessment of periodicals is the count of various indices of their citedness 4 (the total level of a periodical being cited in certain

\footnotetext{
* In the quotations all italicization is done by me - V. L.
} 
specialized periodicals; the quantity or part of citations only to recent papers; calculations of fractions as the number of citations divided by the number of papers published in a cited journal etc.). In order to find an answer to the question "What is the property that is indirectly and very much intermediately reflected by citedness figures?" we are to define first the phenomenon that is directly reflected by citedness. Answers like "scientific activity"5 are true, but not absolutely exact: In general - let us consider only the general trends, but not the plentiful exceptions, - citedness confirms the actual use of scientific documents that has already taken place during the fulfillment of relevant creative work by the authors of citing papers: first, a document is read; then - if it was not thrown away as evidently useless - it is being considered; then - if it is considered to be helpful, - it is used (for comparison, including disproving; assimilation of the methods described etc... etc..); then it is cited (according to the scientific ethics of the author, editorial policy of the publishers etc.).

Once we have agreed that the reflected phenomenon is the use of cited periodicals, it is easier to find the correct term for the reflected property since among the listed terms there is one which meaning is directly associated with the notion of use, viz. "value".

In information science the notion of value of information is defined as "property of information, determined by its fitness for practical use in various spheres of human activity for the achievement of a certain aim". 6 The value of information is directly connected with its $u s e$, be it a single document or a scientific periodical as an organized body of documents: "outside a scientific document the human society does not possess the scientific information, too, since it is namely a document that is a material form of its fixing". ${ }^{7}$ So, it might be clear, that being a method of direct evaluation of the actual use of periodicals, citation count is a method of an indirect evaluation of their value (or, more precisely, their scientific value because the value may also be aesthetical, historical etc. $\left.{ }^{8}\right)$.

We may therefore agree on the following definition: "(Scientific) value of a (scientific) periodical is a property of a periodical to be fit for a use in a (professional scientific) activity of representatives of a certain domain for the achievement of their (professional) aims". This property is independent from the productivity: e.g., a periodical publishing one paper per annum which is cited hundreds of times is more valuable than a journal of ten papers with only one citation each.

However, the terms different from "value" seem to be more frequently used in bibliometric literature to indicate properties reflected by figures of periodical 


\section{S. LAZAREV: CHAOS IN BIBLIOMETRIC TERMINOLOGY}

citedness: "quality", "impact" etc. (e.g. Ref. 5). The examples of vocabulary definitions demonstrate, however, that "quality", "impact" and "value" are not identical notions. It might be seen that "quality" is cognized rather abstractly, not in the process of (or in relation to) the use or satisfaction of the concrete needs, ${ }^{9}$ strongly depending on a cognizing subject ${ }^{10}$ and with the aid of some ideal standards, ${ }^{11}$ whereas "value" relates to the striving, needs, aim $^{12}$ or desire ${ }^{13}, 14$ of a human being, merit or usefulness of an object for a human being, ${ }^{15}, 16$ being determined "not only by its internal structure per se, but also by the fact that an object is involved in the sphere of social human genesis", 17 and in general is being cognized through the "possession and use of "... objects" (cf. Ref. 13). It is obvious, therefore, that quality is an independent property and it is very likely that, if peer assessing may be the appropriate tool for quantitative evaluation of periodicals quality, it is not for value, since it is not based on the periodicals use.

In philosophy the notion of value is treated also as a criterion of preference in a situation of alternative choice, ${ }^{18}$ while for scientific literature, value is treated also as the ability to facilitate to reach the target of the researchers activity. ${ }^{18}$ These definitions are "under the umbrella" of the proposed one: if there is an alternative choice of publications or periodicals, the use of a specific one indicates that the choice has taken place, while if there is no choice but the use of the only possible one, the alternative was "to use or not to use". The second definition of value (Ref. 18 ) is just included in the proposed one.

Two definitions from the general dictionaries give a commonsense idea of what "impact" is: "influence or effect"19 and "a forcible momentary touch, contact or impression". ${ }^{20}$ Citedness, of course, may reflect an influence, effect or a strong impression of cited documents on citing authors, but such an influence (or "impact") of a valuable document is just a consequence of its value. And this consequence is not so much straightforward or compulsory: if a researcher frequently cites a specific paper, it is not known for sure if he has been strongly influenced by it but it is known, that he uses it repeatedly. The opposite situation is even more obvious: one might be strongly impressed by some paper, but, if he/she is not working now in the same direction, he/she would not use it actively and, therefore, would not cite it... and the "impact" of the document would not be reflected. So, we may suppose, that the term "impact", when applied to indicate a property of a highly cited periodical is a more vague term than "value"; therefore - a redundant one. ${ }^{* *}$

\footnotetext{
** The term "impact-factors" denotes a technical indicator, but not a notion, therefore, the mentioned critical discussion does not refer to it.
} 
However, the problem lies not so much in the term itself, but in it's definition. While everybody will understands what we mean with e.g. "significance" of periodicals in association with their citedness, the most important thing is the definition of the property ("a property of a periodical to be fit for a use in a (professional scientific) activity of representatives of a certain domain for the achievement of their (professional) aims"), but not a term.

Another group of regular methods of bibliometric selection and ranking are the quantitative studies of the various kinds of readers activities directed to orientation in periodical publications: searching, finding and - further - (potential) reading of the latter ("spontaneous" requests; requests inspired by reading the abstracts, forwarded earlier to a reader by a system of selective dissemination of information or requests due to some other preliminary information service; requests in a local library or through interlibrary loan etc.; count of time spent by the reader to reading the periodicals in a reading-room; count of the number of the received photocopied articles from various periodicals etc.). Which property is reflected by this group?

Again, to answer the question, it is first necessary to define which phenomenon is reflected by these activities. Despite the discussion about the particularities of the reflected phenomenon, 21,22 hardly anybody would object that the $u$ se of periodicals is the reflected notion. So, the property under assessment is, again, value. That means that all the known methods of periodicals evaluation - normally considered as bibliometric ones*** - reflect only two specific properties: productivity and value. If we would succeed to standardize their definitions, it would be the end of terminological chaos in this area.

However, if the chaos in terminology related to the methods of the second group is in the area of the name of a property, it concerns for the third group the umbrella term for the described kinds of the readers activities. There are a number of conditional umbrella terms fixed in my collection, and paradoxally all these terms are misused standardized terms. These misused terms are: "information request" (see the definition in Refs 24 and 25 "readers demand" (the definition is in Ref. 26), "use of a library stock" 27 and "book output". 28 While the term "information request" has a more expanded meaning, 29, 25 the meanings of "readers demand", "use of library stock" and "book output" are specific and too narrow. In order to overcome these discrepancies, I have proposed the term "readers addressing to scientific periodicals" 30 for designating readers activities directed to orientation in periodicals. Again, my claim is not the

\footnotetext{
*** Some experts believe that quantitative evaluation of the results of peer assessing, questionnaire surveys, interviews etc. are bibliometric methods, ${ }^{23}$ but the majority are of an opposite opinion.
} 


\section{S. LAZAREV: CHAOS IN BIBLIOMETRIC TERMINOLOGY}

term itself, but the evidence for the necessity to standardize some term in this meaning.

Although there seem to be only two specific properties that are bibliometrically assessed in the selecting and ranking periodicals by their ability to correspond to the professional information needs, it does not mean that there are no more specific properties which are the constituents of this general ability including those to be assessed by some new methods to appear in the future. Therefore, an umbrella term to indicate all possible properties under such an assessment is required. Then, in case of "readers addressing..." research, it was demonstrated that the results of some of its kinds, reflecting par exellence periodicals value, are so much influenced by periodicals productivity, that it is not possible to say that productivity is not at all reflected, and value is the only reflected property (see Ref. 30). And, finally, a lot of conditional umbrella terms are actually used.

To overcome this situation, I propose the umbrella term "thematic orientation of periodicals" (used first in Ref. 31 and being a subject of Ref. 32). Being originally coigned in Russian, it may not sound neat enough in its English translation, and so my claim is not the term itself. All I claim is the demonstration of the necessity to standardize an appropriate term with the mentioned umbrella meaning.

It should be understandable that my paper is only an illustration of the importance of standardization of bibliometric terminology. It is obvious that even in the framework of the above speculations we need to be more concrete about terms like "property", "indicator", "quantitative assessment", "measurement" and so on.

The author is indebted to Professor V.M. Motylev from Sankt-Petersburg who taught him to be a pedant in terminology. This paper would also hardly be written if it were not for ideological support from Professor Ona Voverenye (Vilnius, Lithuania) and Dr. Galina M. Abeleva (Sankt-Petersburg, Russia).

\section{References}

1. S.C. BRADFORD, Sources of information on specific subjects, Engineering, 137 (1934) $85-86$.

2. Dictionary of the Terms of the Information Science, International Center for Scientific and Technical Information, Moscow, 1975, p. 350. (in Russian, with the applied lists of terms in 13 more languages).

3. S.D. Hattun, Scientometrics, Nauka, Moscow, 1983, (in Russian).

4. P.L.K. Gross, E.M. Gross, College libraries and chemical education, Science, 66 (1927) 385-389.

5. L. SALMI, Citation analysis and impact factor, Newsletter to European Health Libraries, No. 28 (1994) 17-18. 


\section{S. LAZAREV: CHAOS IN BIBLIOMETRIC TERMINOLOGY}

6. Dictionary of the Terms of the Information Science, 1975, Op. cit., p. 464.

7. A.I. Mikhailov, A.I. Chernury, R.S. GilarevskyI, Scientific Communications and the Information Science, Nauka, Moscow, 1976 (in Russian).

8. L. M. TolchinSKaYA, Criteria for the [documents] selection for library stocks formation, Sovetskoye bibliotekovedeniye, No. 3 (1985) 47-54 (in Russian).

9. E.L. Radlov (Ed.), Brokgauz - Efrom, Philosophical Dictionary: Logic, Psychology, Ethics, Aesthetics and the History of Philosophies, Sankt-Petersburg, 1904, p. 127 (in Russian).

10. E.L. RaDLov, 1904, Op. cit., p. 127.

11. Encyclopedia Britannica, Vol. 18, William Benton Publ., Chicago - London - Toronto - Geneva - Sydney - Tokyo - Manila, 1969, p. 915.

12. E.L. RaDlov, 1904, Op. cit., p. 265.

13. R.H.I. INGLIS Palgrave (Ed.), Dictionary of Political Economy, Vol III, MacMilian and Co., Ltd., London, 1901, p. 606.

14. Websters's Desk Dictionary of the English Language Based on the Classic Edition of the Random House Dictionary, Portland House, New York, 1993, p. 990.

15. Websters's Desk Dictionary of the English Language Based on the Classic Edition of the Random House Dictionary, 1993, Op. cit., p. 990.

16. Websters's New Twenties Century Dictionary of the English Language. Unabridged. 2nd ed., The World Publ. Co., Cleveland and New York, 1968, p. 2018.

17. Philosophical Dictionary, Politizdat, Moscow, 1972, p. 453.

18. V.A. Minkina, Investigations of documentary flows for assessment the characteristics of value of technical literature, In: Documentary Flows on Natural Sciences and Technology and Bibliographical Problems: Collected Papers, Leningrad, 1983, p. 111-122 (in Russian).

19. Websters's Desk Dictionary of the English Language Based on the Classic Edition of the Random House Dictionary, 1993, Op. cit., p. 451.

20. Websters's New Twenties Century Dictionary of the English Language, 1968, Op. cit, p. 910.

21. P.A.Scales, Citation analysis as indicator of the use of serials: a comparison of ranked titles lists produced by citation counting and from the use data, Journal of Documentation, 32 (1977) 17-25.

22. V.S. LAZAREV, Readers request analysis in documentation (Concerning the paper by W.I.B. ONUIGBO), International Forum on Information and Documentation, 11 (1986) 40-41.

23. D. Schmidmaier, Application of bibliometrics in technical university libraries, In: Developing Library Effectiveness for Next Decade. Proceedings of the 7th Meeting. LATUL, Leuven, 1977, 16-22 May, Goeteborg, 1978, p. 129-135.

24. Dictionary of the Terms of the Information Science, 1975, Op. cit., p.165.

25. State Standard [of the USSR] 7.27-80: Scientific information activity. Basic terms and definitions: Insulated since 01.01 .82$, p. 2 (in Russian).

26. Vocabulary of Library Terms, Kniga, Moscow, 1976, p. 191-192 (in Russian).

27. Vocabulary of Library Terms, 1976, Op. cit., p. 58.

28. Vocabulary of Library Terms, 1976, Op. cit., p. 69-70.

29. Dictionary of the Terms of the Information Science, 1975, Op. cit., p.165.

30. V.S. LAZAREV, Readers addressing to scientific periodicals as an indicator of periodicals thematic orientation, In: Methodological Problems of Medical Information Science and the Science of Science in Medicine: Collected Papers, Moscow, 1989, p. 173-186 (in Russian).

31. V.S. LAzAREV, Analysis of biblioraphical citations as a method of selection thematically oriented periodicals, Naucniuye i tekhnicheskiye biblioteki SSSR, No. 5 (1981) 27-34 (in Russian).

32. V.S. LAZAREV, Quantitative assessment of thematic orientation of scientific periodicals, Naucniuye $i$ tekhnicheskiye biblioteki SSSR, No. 3 (1983) 22-29 (in Russian). 